\title{
Isolation and Characterization of Homeodomain-Leucine Zipper III Protein 1 Gene in Poplar
}

\author{
Hyoshin Lee ${ }^{1 *}$, Eung-Jun Park ${ }^{1}$, Seo-Kyung Yoon ${ }^{1}$, Mi Na Choi ${ }^{1}$, Soo Hyung Eo ${ }^{2}$ \\ ${ }^{1}$ Department of Forest Genetics and Resources, Korea Forest Research Institute, Suwon 441-847, Republic of Korea \\ ${ }^{2}$ Department of Forest Resources, Kongju National University, Yesan 340-702, Republic of Korea
}

\begin{abstract}
Transcription factors are the regulatory proteins which activate or repress their target genes. We isolated homeodomainleucine zipper III (PagHD-ZIP III_ 1) gene, a plant-specific transcription factor known to play crucial roles in plant development, from poplar (Populus alba $\times$ P. glandulosa). The PagHD-ZIP III_l is 2,723 base pairs long and encodes a putative 838 amino acid protein with an expected molecular mass of $92.3 \mathrm{kDa}$. The PagHD-ZIP III_1 protein has four conserved regions including HD, bZIP, START and MEKHLA. Southern blot analysis indicated that PagHD-ZIP III_l belong to a small gene family in the poplar genome. PagHD-ZIP $I I I$ I is expressed highly in the stem. Moreover, the expression of PagHD-ZIP III_l is induced by salt, cold, wounding and a plant hormone JA. Our results indicate that PagHD-ZIP III_l is involved in abiotic stress response and hormonal signaling in poplar.
\end{abstract}

Keywords Jasmonic acid, PagHD-ZIP III_1, Populus alba $\times$ P. glandulosa, Stress, Transcription factor, Wounding

\section{INTRODUCTION}

Transcription factors (TFs) in eukaryotes are important regulatory proteins, which activate or repress the expression of their target genes by binding to specific DNA sequences adjacent to the genes (Long and Benfey 2006). TFs play significant roles in the response and adaptation of plant to various types of abiotic stress. Recently, fine-tuning of TF expression has shown to increase plant biomass and abiotic stress tolerance in a number of plant species (Jeong et al. 2012; Lindemose et al. 2013).

Homeodomain-leucine zipper (HD-ZIP) proteins are a plant specific TF, which plays an important role in the plant development (Elhiti and Stasolla 2009). HD-ZIP proteins contain homeodomain (HD) and leucine zipper (LZ) motif. The HD domain is involved in the specific binding to DNA by its helix III, while the LZ domain has the ability to dimerize, which is necessary for binding to the target sequence (Johannesson et al. 2001). The HD-ZIP proteins are divided into four subfamilies (HD-ZIP I, II, III, and IV) based on their sequence conservation, structural features and functions (Hu et al. 2012). HD-ZIP III proteins have been extensively implicated in the regulation of primary and secondary vascular tissue pattern formation as well as lateral organ and cambial polarity in woody plants (Côté et al. 2010).

Arabidopsis thaliana contains 48 members of HD-ZIP genes including five HD-ZIP IIIs, which have key roles in the development process (Prigge et al. 2005). The functionally well-characterized HD-ZIP class III includes five genes PHABULOSA(PHB)/ATHB14, PHAVOLUTA(PHV)/ATHB9, REVOLUTA (REV)/INTERFASCICULAR FIBERLESSI(IFL1), which direct the development of the apical meristem, the vascular bundles, and the adaxial domains of lateral, and ATHB8, and CORONA(CNA)/ATHB15/INCURVATA4 (ICU4), which have been suggested to direct vascular development (Emery et al. 2003; Green et al. 2005). Compared to the largely investigated functions of Arabidopsis HD-ZIPs, only two Populus HD-ZIP genes (POPREVOLUTA and POPCORONA) have recently been characterized. These two HD-ZIP III genes are largely involved in regulating cell differentiation during secondary growth (Robischon

Received August 6, 2013; Revised August 26, 2013; Accepted August 27, 2013

*Corresponding author Hyoshin Lee, hslee@forest.go.kr, Tel: +82-31-290-1174, Fax: +82-31-290-1020 
et al. 2011).

In recent years, a number of researches have been conducted to increase lignocellulosic biomass as a promising alternative energy source. Since HD-ZIP III genes have shown to regulate xylem development and cell wall biosynthesis, tree breeding program can use them to identify molecular markers and to improve plant growth traits. In this study, we isolated PagHD-ZIP III_l and analyzed its characteristics and expression patterns.

\section{MATERIALS AND METHODS}

\section{Plant materials and growth conditions}

Leaf suspension cells of poplar (Populus alba $\times P$. glandulosa) were cultured in the MS medium (Murashige and Skoog 1962) containing 2,4-dichlorophenoxyacetic acid $1.0 \mathrm{mg} / \mathrm{L}$, 1-naphthalene acetic acid $0.1 \mathrm{mg} / \mathrm{L}$, 6-benzylaminopurine $0.01 \mathrm{mg} / \mathrm{L}$, and sucrose $30 \mathrm{~g} / \mathrm{L}$. Cells were sub-cultured every three to four weeks when they reached the stationary phase by adding $0.4 \mathrm{~g}$ fresh cellular mass to $100 \mathrm{ml}$ of liquid MS medium and maintained at $22 \pm 1{ }^{\circ} \mathrm{C}$ under $20 \mu \mathrm{mol} \mathrm{m}{ }^{-2} \mathrm{~s}^{-1}$ cool-white fluorescent light with constant agitation at $130 \mathrm{rpm}$ (Lee et al. 2005). To examine tissue-specific gene expression patterns, leafand stem-tissues were collected from one-year-old poplar trees and flower-tissues were harvested from 25-year-old trees.

\section{Isolation and characterization of HD-ZIP III gene}

A poplar cDNA library was constructed as described previously in Lee et al. (2005). For expressed sequence tag analysis, the cDNA library was randomly excised in vivo using the ExAssist helper phage (Stratagene, CA, USA). The plasmid DNAs were isolated and $5^{\prime}$-single pass sequences were determined. Searches of the public databases were made with BLASTX to select clones homologous to known plant HD-ZIP III genes. The selected cDNA clone was sequenced and then analyzed its amino acid sequence and molecular weight by Vector NTI advance 10.0 (Invitrogen, CA, USA). Alignment and phylogenetic trees were generated by the ClustalW, based on cDNA sequence or deduced amino acid sequences of HD-ZIP III gene. Finally, the analysis for conserved domain was conducted by Batch Web CD-Search Tool (http://www.ncbi.nlm.nih. gov/ Structure/bwrpsb/bwrpsb.cgi).

\section{Genomic DNA isolation and Southem blot analysis}

Genomic DNA was extracted from leaves using MegaExtractor plant genome kit (Toyobo, Japan) and $10 \mu \mathrm{g}$ of DNA was digested overnight with the restriction enzymes EcoRI, HindIII or XbaI. The DNA was then separated on an $1 \%$ agarose gel and transferred to a Hybond-XL nylon membrane (Amersharm-Pharmacia, NJ, USA) using the capillary transfer method (Southern 1975). The membrane was prehybridized at $68^{\circ} \mathrm{C}$ for $30 \mathrm{~min}$ in $1 \times$ PerfectHYB plus hybridization buffer (Sigma- Aldrich, USA) and 0.1 $\mathrm{mg} / \mathrm{mL}$ sheared, single-stranded herring sperm DNA. Subsequently, ${ }^{32} \mathrm{P}$-dCTP labelled full-length PagHD-ZIP III_l probe was added and hybridized at $68^{\circ} \mathrm{C}$ for $12 \mathrm{~h}$. Following hybridization, the membrane was washed three times in $0.2 \times \mathrm{SSC}$ and $0.1 \% \mathrm{SDS}$ at $65^{\circ} \mathrm{C}$ for $10 \mathrm{~min}$. Detection was done by exposure to an X-ray film at $-70^{\circ} \mathrm{C}$.

\section{Abiotic stress and plant hormone treatment}

To induce gene expression in response to osmotic stress, 4-day-old suspension cultures were treated with $250 \mathrm{mM}$ mannitol or $150 \mathrm{mM} \mathrm{NaCl}$. The suspensions were maintained at $2{ }^{\circ} \mathrm{C}$ for cold treatment, and were treated with $20 \mu \mathrm{M}$ ABA, $20 \mu \mathrm{M}$ gibberellic acid $\left(\mathrm{GA}_{3}\right), 10 \mu \mathrm{M}$ jasmonic acid (JA), and $20 \mu \mathrm{M}$ salicylic acid (SA) for plant hormone responses. For wounding treatment, the leaves of one-yearold plants were collected after being trimmed along their edge with sterile scissors. All suspensions and leaves were immediately frozen in liquid nitrogen and stored at $-70^{\circ} \mathrm{C}$ for further gene expression analysis.

\section{RNA isolation and real-time quantitative PCR}

Total RNA was extracted using TRI reagent (Molecular Research Center, OH, USA) and RT-qPCR primers were designed by using Primer3 program (http://fokker. wi. mit.edu). As a quantitative control, poplar actin gene was used (Kim et al. 2010). PagHD-ZIP III_I was amplified with a forward primer $\left(5^{\prime}\right.$-TCCCTCCTGCAATCCTTCTGA 
$\left.-3^{\prime}\right)$ and a reverse primer $\left(5^{\prime}\right.$-CCTTCCAGTTTTATCACCTCCAGG $\left.-3^{\prime}\right)$, while actin was amplified with a forward primer (5'-GCCATCTCTCATCGGAATGG-3') and a reverse primer ( $5^{\prime}$-AGGGCAGTGATTTCCTTGCT- $\left.3^{\prime}\right)$. Gene expression levels were determined using $2^{-\triangle \Delta \mathrm{Ct}}$ method (Livak and Schmittgen 2001).

First-strand cDNA synthesis was performed using a PrimeScript RT Reagent Kit (Takara, Japan) and RT-qPCR was conducted using SYBRGreen PCR Master Mix (BioRad laboratories, USA), according to the manufacturer's instructions. RT-qPCR was carried out using the DNA Engine Opticon ${ }^{\mathrm{TM}}$ Continuous Fluorescence Detection System (MJ Research Inc., Walthan, MA). All PCR mixtures contained: $1 \mu \mathrm{L}$ of cDNA, $10 \mu \mathrm{L}$ of $2 \times$ SYBRGreen PCR Master Mix, $1 \mu \mathrm{L}$ of each PCR primer $(10 \mu \mathrm{M})$, and 7 $\mu \mathrm{L}$ of nuclease-free water in a $20 \mu \mathrm{L}$ of final volume reaction mix. The cycling conditions for amplification included $10 \mathrm{~min}$ at $95^{\circ} \mathrm{C}$ for polymerase activation, followed by 40 cycles of $95^{\circ} \mathrm{C}$ for $30 \mathrm{sec}, 60^{\circ} \mathrm{C}$ for $30 \mathrm{sec}$, and $72^{\circ} \mathrm{C}$ for $30 \mathrm{sec}$.

\section{RESULTS AND DISCUSSION}

\section{Isolation and structural characterization of HD-ZIP III_1 gene}

We selected a poplar cDNA clone from the cDNA library that had been prepared from poplar suspension cells (Lee et al. 2005) and compared it with previously identified plant HD-ZIP III genes using a BLAST search. DNA sequence of the full cDNA clone was $98 \%$ identical to HD-ZIP III (AY919621.1) of Populus trichocarpa, $87 \%$ to HD-ZIP ATHB-15 like isoform 1 (XM_002283967.1) of Vitis vinifera, and $80 \%$ to $A T H B-15$ (EU550335.1) of Arabidopsis thaliana. Therefore, we named this cDNA clone as PagHD-ZIP III_I (Populus alba $\times$ P. glandulosa HD-ZIP III 1).

An open reading frame of PagHD-ZIP III_l was 2,514 bp long (Fig. 1). The estimated molecular mass of the putative protein, which consisted of 838 amino acids (aa) residues, was $92.3 \mathrm{kDa}$ and its isoelectric point was 6.09 . The major component of deduced amino acids consisted of $10.5 \%$ of leucine, $8.7 \%$ of serine, and $8.2 \%$ of alanine. The identified HD-ZIP genes in Populus encode proteins ranging from 70 to 855 amino acids in length with an average of 465 aa (Hu et al. 2012).

HD-ZIP III proteins contain four conserved regions $(\mathrm{Hu}$ et al. 2012). When the aa sequence of PagHD-ZIP III_I was compared with other plant HD-ZIP III proteins, all four regions were shown to be well conserved (Fig. 2). Unique features of all HD-ZIP proteins are the presence of the HD domain, which binds to the specific DNA sequence, and ZIP domain, which dimerizes proteins to bind to the target sequence (Johannesson et al. 2001). It is also known that HD-ZIP III and IV contain a steroidogenic acute regulatory protein related lipid-transfer (START) domain (Schrick et al. 2004). One of the defining features of HD-ZIP III proteins is the presence of a MEKHLA domain at the $\mathrm{C}$ terminus, which is involved in light, oxygen, and redox potential sensation (Ohashi-Ito and Fukuda 2003). MEKHLA domain shares significant similarity with the PAS domain, reported to dimerize with the AP2 domain of the transcription factor DRN/ESR-1 involved in embryo patterning and auxin transport (Mukherjee and Bürglin 2006).

The amino acid sequence of PagHD-ZIP III protein was at maximum 99\% identical to PtrHox 16 (Poptri.003G050100) in P. trichocarpa, 91\% to MdHB15 (ACI13685.1) in apple (Malus $\times$ domestica), and 87\% to ATHB-15 (NP_175627.1) in A. thaliana (Fig. 2). Consequently, we concluded that PagHD-ZIP III_l isolated in this study is a member of plant HD-ZIP III.

\section{Southem blot hybridization}

In order to investigate how many copies of PagHD-ZIP III_l genes are present in poplar (Populus alba $\times P$. glandulosa), Southern blot analysis was performed. A full-length of PagHD-ZIP III_l cDNA probe was hybridized with genomic DNA, which was digested with EcoRI, $H i n d I I I$, and $X b a \mathrm{I}$, respectively. In a result, all lanes showed five to seven bands (Fig. 3), suggesting that the PagHDZIP III_l gene belonged to a multi-copy gene family in Populus alba $\times P$. glandulosa. Previous reports were also shown that the number of HD-ZIP III genes were different between plant species. For example, Arabidopsis HD-ZIP III subfamily comprises of only five genes (Prigge et al. 2005), while $P$. trichocarpa has 8 genes (Hu et al. 2012), 
which possesses a number of introns (as many as 17) (Hu et al. 2012). Côté et al. (2010) also demonstrated that transcripts of HD-ZIP III genes differed in abundance depending on organs and tissues, with a strong indication of functional diversification between the gene families. Therefore we assumed that the PagHD-ZIP III_l gene might also play different roles in the organ- or tissue-specific manner.

\section{Tissue-dependent expression pattem of PagHD-ZIP III_1}

Comparative expression analysis of PagHD-ZIP III_l in leaf, stem, flower, and suspension cells, revealed that the transcript was most abundant in stem tissues (Fig. 4). $P$. trichocarpa has eight members of HD-ZIP III genes, which shows tissue-specific expression pattern (Hu et al. 2012). For example, PtrHox 5, 7, and 16 were highly expressed in shoot tip, cambium layer, and root, while higher expression

1 ATGGCAATGTCCTGCAAGGATGGTAAGCAGCCTATCATGGACAATGGCAAGTATGTCCGGTACACGCCTGAGCAGGTCGAAGCCCTGGAAAGGCTCTAT

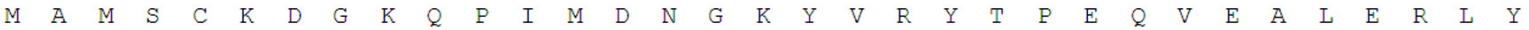

100 CATGATTGTCCCAAACCCAGCTCCATTCGCCGCCAGCAGCTCATTAGGGAGTGTCCAATTCTCTCCAACATTGAGCCCAAACAAATCAAAGTTTGGTTT

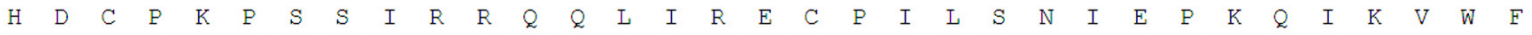

199 CAAAATAGAAGATGCGAGAGAAGCAGAGGAAAGAGGCGTCTCGCCTCCAGGCGGTGAATAGGAAGCTGACTGCAATGAACAAGCTTCTGATGGAAGAG

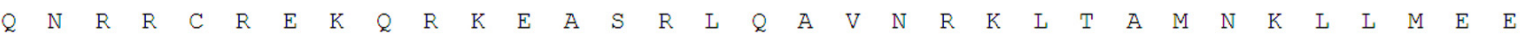

298 AATGATAGGTTGCAGAAGCAGGTGTCGCAGCTGGTGTATGAGAATGGGTACTTTCGCCAACATACCCATAACACACCGCTTGCAACCAAAGATACAAGC

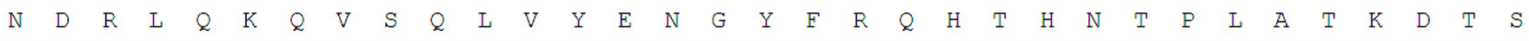

397 TGT GAATCAGTGGTGACAAGCGGTCAACACCACCTGACACCTCAGCATCCGCCAAGGGATGCTAGTCCTGCAGGGCTTTTGTCCATTGCAGAAGAGACT

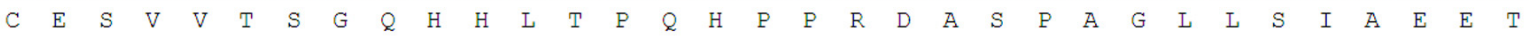

496 TTAACAGAGTTCTTTCAAAGGCTACTGGAACTGCTGTAGAGTGGGTCCAAATGCCTGGAATGAAGCCTGGTCCGGATTCCAGTGGAATCGTTGCTATT

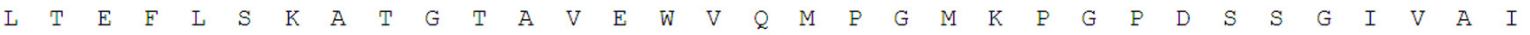

595 TCTCATGGTTGTACTGGCGTGGGAGCACGAGCTTGTGGCCTAGTGGGTCTAGAACCTACAAGGGTTGCTGAAGTCCTCAAGGATCGGCCATCATGGTTT

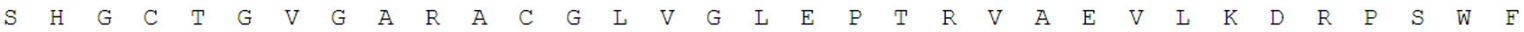

694 CGTGATTGCCGAGCTGTGGATGTGCTTAATGTGCTGCCCACCGCAAATGGTGGAACCATTGAGCTGCTTTATATGCAGCTCTATGCCCCAACTACGTTG

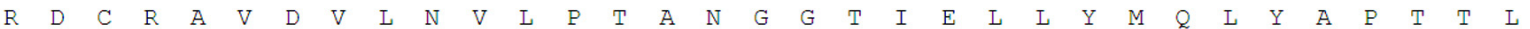

793 GCACCTGGTCGTGACTTCTGGTTGTTGCGTTATACTTCTGTTTTAGAAGATGGAAGCCTTGTGGTATGTGAGAGATCACTGAAAAATACTCAGAATGGC

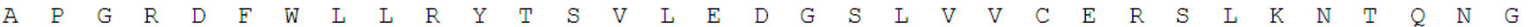

892 CCGAGCATGCCACCAGTGCAGCATTTTGTGAGAGCAGAAATGCTCCCAAGTGGGTATCTGGTACGGCCTTGTGAAGGTGGTGGTTCAATTATACACATA

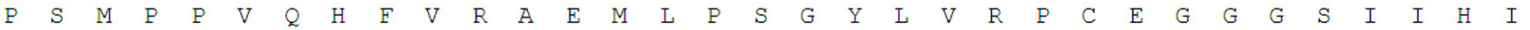

991 GTTGACCACATGGATTTGGAGCCTTGGAGTGTGCCTGAAGTACTACGGCCGTTGTATGAATCCTCAACTGTACTTGCTCAAAAGACAACAATGGTGGCT

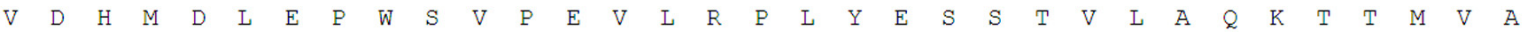

1090 CTACGCCAGCTGCGGCAGATAGCTCAGGAAGCTTCTCAGTCTAATGTGACCAACTGGGGCAGACGACCTGCAGCTCTACGAGCACTGAGCCAGAGGTTG

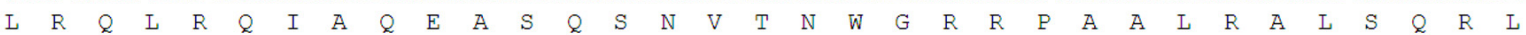

1189 AGCAGGGGTTTTAATGAGGCTCTCAATGGATTTAGTGATGAGGGATGGTCAATGATTGGAAATGATGGCATGGATGATGTTACTATCCTCGTGAACTCA

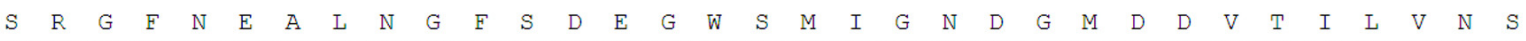

1288 TCTCCTGACAAGTTGATGGGTTCAAATCTTTCCTTCACTAATGGGTTTCCAGCTGTCAGCAGTGCTGTCCTGTGTGCTAAAGCATCGATGCTTTTACAG

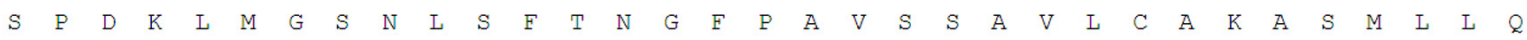

1387 AATGTCCCTCCTGCAATCCTTCTGAGATTCTTGCGAGAGCACAGGTCAGAATGGGCAGATAACAATATTGATGCCTATGCAGCTGCAGCGGTTAAAGTT

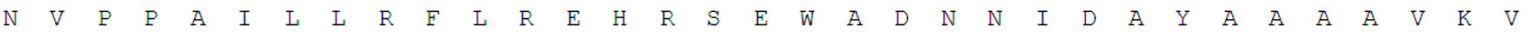

1486 GGTCCTTTAGCTTACAAGGTTCTCGAGTTGGAAGTTTCGGGGGTCAAGTTATACTTCCGCTGGCTCACACTATTGAACATGAAGAGTTCCTGGAGGTC

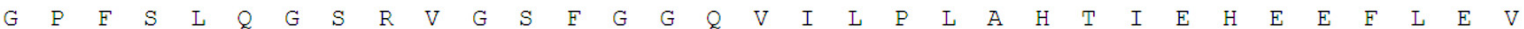

1585 ATAAAACTGGAAGGTGTTGGCCATTCTCCTGAAGATCCAATAATGCCCAGAGATGTGTTTCTTTTGCAACTCTGCTGTGGAATGGACGAGAATGCTGTT

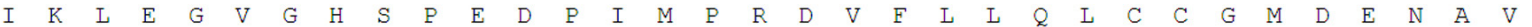

1684 GGCGCATGTGCTGAACTTATATTTGCTCCCATTGATGCGACTTTTGCTGATGATGCACCGCTTTTACCTTCTGGTTTCGCATCATTCCCCTTGATTCT

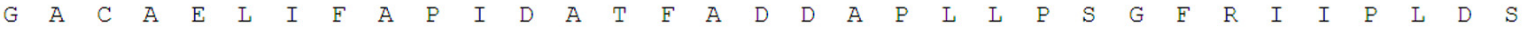

1783 GGGAAGGAAGCCTCCAGTCCAAATCGTACCTTAGATCTTGCGGCTGCTCTTGAAGTCGGACCAGCTGGAAACAGAGCATCCAGTGATCATTCTGCTAAT

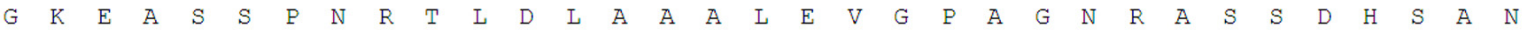

1882 TCTGGTTGCACAAGATCTGTAATGACAATCGCATTTGAATTGCATTTGAGAGCCACATGCAAGAACATGTAGCATCAATGACTCGGCAATATATCCGA

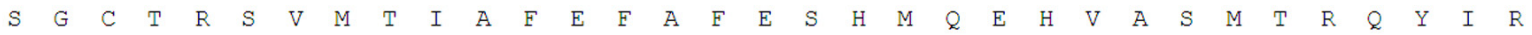

1981 AgCATTATATCTTCAGTTCAGAGGGTGGCATTAGCACTATCTCCTTCTCATCTTGGTTCACAGGCTGGTCTTCGGTCACCACTGGGTACTCCTGAAGCA

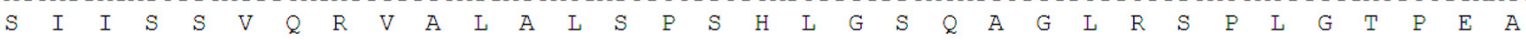

2080 CAGACACTTGCTCGTTGGATCTGCCAGAGCTACAGGAGCTATTTGGGTGTGGAGCTACTCAAATCCAATGGCGAAGGAAGTGAATCTATTCTGAAAACC

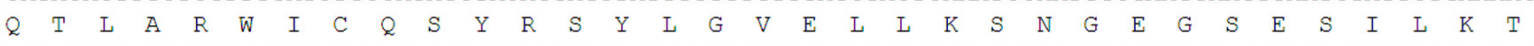

2179 TTGTGGCATCATTCAGATGCTATTATGTGCTGCTCATTGAAGGTGTTGCCCGTCTTTACTTTTGCAAACCAAGCTGGACTTGACATGCTTGAGACAACA

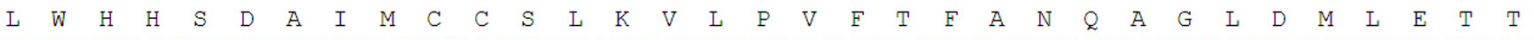

2278 TTAGTTGCACTGCAAGACATAACTTTGGAAAAGATATTTGATGATCATGGAAGAAAAACTCTCTGCTCAGAATTCCCACAGATCATGCAACAGGGTTTT

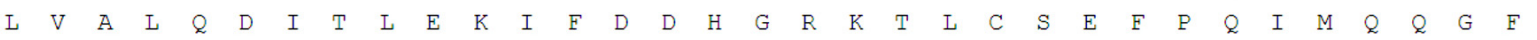

2377 ACTTGTCTTCAAGGCGGTATCTGTTTGTCAAGCATGGGCAGACCAGTTTCATATGAAAGAGCTGTGGCCTGGAAAGTGTTGAATGAAGAAGAAAATGCG

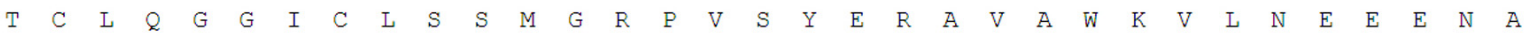

2476 CATTGCATCTGCTTTATGTTTATAAACTGGTCTTTTGTCTGAGACTTGAAACCAGAATCTAGTGGAGTGGCTGATTTAAGAGTGAGAACTCTATACCTG $\begin{array}{llllllllllllllllllllll}H & C & I & C & F & M & F & I & N & W & S & F & V & *\end{array}$

2575 TCTTATTTGCTGGCTTGTATTTCTCTATGTATAACATGTTACAACCGTGGAGCACCTAGTTCATTTGCTATGTTATAAATTGTGTGGGGTTTGTTA 2674 TCGTAGAGATTATGGACGAGACGATCTAGTTGCCGGGGATCATTTTGTTT

Fig. 1. Nucleotide and deduced amino acid sequences of the PagHD-ZIP III_1. A stop codon is indicated by an asterisk (*). 
levels of PtrHox44 and 61 were found in shoot tip, cambium layer, root, and phloem tissues. Hu et al. (2012) also revealed that PtrHox31 genes showed the highest transcript abundance in both differentiating xylems and roots with much lower expressions in cortex and leaf tissues, while PtrHox23 genes were expressed much higher

HD

PagHD-ZIPIII

PtrHoxl6

MaHB15

ATHB-15

PagHD-ZIPIII

PtrHox16

MdHB15

ATHB-15

PagHD-ZIPIII

PtrHox16

MaHB15

ATHB-15

PagHD-ZIPIII

PtrHox16

MdHB 15

ATHB-15

PagHD-ZIPIII PtrHox16

MdHB 15

ATHB-15

PagHD-ZIPIII

PtrHox16

MdHB15

ATHB-15

PagHD-ZIPIII

PtrHox16

MdHB 15

ATHB-15

PagHD-ZIPIII

PtrHox16

MdHB15

ATHB-15

PagHD-ZIPIII

PtrHox16

MdHB15

ATHB-15

PagHD-ZIPIII

PtrHox16

MdHB15

ATHB-15
MAMSCKDGKQP IMDNGKYVRYTPEQVEALERLYHDCPKPSS IRRQQLIRECPILSNIE PKQIKVWFQNRRCREKQRKEASRLQAVNRKLT MEMSCKDGKQPIMDNGKYVRYT PEQVEALERLYHDCPKPS S IRRQQL I RECPILSN IE PK IKVWFQNRRCREKQRKEASRLQAVNRKLS MAMSCKDGNKHALDNGKYVRYTPEQVEALERLYHDCPKPSS IRRQQL I RECPI LSN IE PKQI KVWFQNRRCREKQRKEASRLQAVNRKLS MAMSCKDGKL GCLDNGKYVRYTPEQVEALERLYHDCPKPSS IRRQQL IRECPILSNIE PKQIKVWFQNRRCREKQRKEASRLQAVNRKLI

\section{bZIP}

AMNKLLMEENDRLQKQVSQLVYENGYFRQHTHNTPLATKDTSCESVVTSGQHHLTPQHPPRDAS PAGLLS IAEETLTEFLSKATGTAVEW 180 AMNKLLMEENDRLQKQVSQLVYENGYFRQHTHNTPLATKDTSCESVVTSGQHHLTPQHPPRDASSAGLLS IAEETLTEFLSKATGTAVEW 180 AMNKLLMEENDRL $Q$ KVVSHLVYENGYFRQHTQGTTLATKDTSCESVVTSGQHHLTPQHPPRDAS PAGLLS IAEETLAEFLSKATGTAVEW 180 AMNKLLMEENDRLQKQVSQLVHENSYFRQHTPNPS LPAKDTSCESVVTSGQHQLASQNPQRDASEAGLLS IAEETLAEFLSKATGTAVEW 180

\section{START}

VOMPGMKPGPDSSGIVAISHGCTGVGARACGLVGLEPTRVAEVLKDRPSW FRDCRAVDVLNVL PTANGGT IELLYMOLYAPTTLAPGRDF 240 VQMPGMKP GP DSSGIVAISHGCAGVGARACGLVGLEPTRVAEI LKDRPSWFRDCRAVDVLNVL PTANGGT IELLYMQLYAPTTLAPGRDF 240 VQMPGMKPGP DS I GIVAISHGCTGVAARACGLVGLEPTRVAEILKDLPSWLRDCRAVDVLNVL PTANGGT IELLYMQLYAPTTLAPACDF 240 VQMPGMKPGP DS IGI IAISHGCTGVAARACGLVGLEPTRVAEIVKDRPSWFRECRAVEVMNVL PTANGGTVELLYMQLYAPTTLAPPRDF 240

WLLRYTSVLE DGSLVVCERS LKNTQNGPSMPPVQHFVRAEMLPSGYLVRPCEGGGS I IHIVDHMDLEPWSVPEVLRPLYESSTVLAQKTT 360 WLLRYTSVLE DGSLVVCERS LKNTQNGPSMPPVQH FVRAEMLPSGYLVRPCEGGGS I I I VDHMDLEPWSVPEVLRPL YESSTVLAQKTT 360 WLIRYTSVLE DGS LVVCARS LKNTQNGPTMPPVQH FVRAEMLPSGYL IRPCEGGGS I I I I VDHMDLEPCSVPEVLRPL YES SAVLAQKMT 360 WLIRYTSVLE DGSLVVCERS LKST QNGPSMPLVQNFVRAEMLSSGYL IRPCDGGGS I I I VDHMDLEACSVPEVLRPLYESPKVLAQKTT 360

MVALROLROI ADEASQSN--VTNWGRRPAALRALSORLSRGFNEALNGFS DEGWSMI GND GMDDVTILVNSS PDKLMGSNLSFTNGFPAV 448 MVALRQLRQI ACEASQSN--VTNWGRRPAALRALSQRLSRGFNEALNGFS DEGWSMI GND GMDDVTILVNSSPDKLMGSNLSFTNGFPAV 448 MAALRQLRQI AHEVSQSN--VTGWGRRPAALRALS QRLSRGFNDALNGFT DEGWSMMGND GMDDVTILINSS PDKLMGLNLSFGNGFPAV 448 MAALRQLKQI AQEVTQTNSSVNGWGRRPAALRALSQRLSRGFNEAVNG FT DEGWSVIG-DSMDDVTITVNSSPDKLMGLNLTEANGFAPV 450

SSAVLCAKASMLLQNVPPAILLRFLREHRS EWADNNIDAYAAAAVKVGPFSLQGSRVGSFGGQVILPLAHT IEHEEFLEVIKLEGVGHSP 538 SSAVLCAKASML LQNVPPAI LLRF LREHRS EWADNN I DAYAAAAVKVGPF SLQGSRVGSEGGQVILPLAHTIEHEEFLEVIKLEGVGHSP 538 SNSVLCAKASMLLQNVPPAI LLRELREHRS EWADNNIDAYSAAAVKVGPCSLAGSRVGSFGGQVILPLAHTLEHEEFLEVIKLEGVGHSP 538 SNVVLCAKASMLLQNVPPAI LLRFLREHRS EWADNN IDAY LAAAVKVGPCSAR---VGGEGGQVILPLAHTIEHEEFMEVIKLEGLGHSP 536

EDP IMPRDVF LLQLCCGMDENAVGACAELI FAPI DATFADDAPLLPSGFR I I PLDSGKEASS-PNRTLDLAAALEVGPAGNRASSDHSAN 627 EDP IMPRDVE LLQLCCGMDENAVGTCAELI FAPI DATFADDAPLLPSGFRI I PLDSGKEASS-PNRTLDLAAALEVGPAGNRASSDHSAN 627 EDAMMPREMF L LQLCSGMDENAVGSCAELI FAPIDASFADDAPLLPSGFRI I PLDYGKEASS-PNRTLDLASALEIGPTGNKGSSEYSAS 627 EDAIVPRDI FLLQLCSGMDENAVGTCAEL I FAPI DASFADDAPLLPSGFR I I PLDSAKOEVSS PNRTLDLASALEIGSAGTKASTDQSGN 630

SGCTRSVMTI AFE FAFESHMQEHVASMTRQYIRS I ISSVQRVALALS PSHLGSQAGLRSPEGT PEAQTLARWICQSYRSYLGVELLKSNG 717 SGCTRSVMTI AFE FAFESHM QEHVA.SMTRQYIRS I ISSVQRVALALSP-HLGSQAGLRSP EGT PEAQTLARWICQSYRSYLGVELLKSNG 716 AGCVRSVMTI AFE FACETHMQEHVASMARQYVRS I ISSVQRVALALS PSNLSSQAGLRSP LGT PEAQT LARWICNSYRCYLGVELLKSGN 717 STCARSVMTI AFE FGIESHMQEHVASMARQYVRG I ISSVQRVALALS PSH ISSQVGLRT PEGT PEAQTLARW ICQSYRGYMGVELLKSNS 720

\section{MEKHLA}

EGSES I LKT LWHHS DA IMCC S LKVLPVFTFANQAGL DMLETTLVALQD IT LEKI FDDHGRKTLCSEFPQIMQQGFTCLQGG ICLSSMGRP 807 EGSES ILKTLWHHS DA IMCCS LKALP I FT FANQAGL DMLETTLVALQDITLEKI FDDHGRKTLCSEFS IMQQGFTCLQGGICLSSMGRP 806 EGSESILKSLWHHSDA IMCCSLKAL PVFTF ANQA GLDMLETTLVALQDIT LEKI FDDHGRKTLCSEFP IMQQGFTCLQGG ICLSSMGRP 807 DGNESI LKNLWHHTDA I ICCSMKALPVFTFANQAGLDMLETTLVALQDISLEKIFDDNGRKTLCSEFPQIMQQGFACLQGG ICLSSMGRP 806

Fig. 2. Multiple alignment of the deduced amino acid sequences of PagHD-ZIP III_l with HD-ZIP III from P. trichocarpa (PtrHox16), Malus $\times$ domestica (MdHB15) and A. thaliana (ATHB-15). The alignment was produced using ClusterW2. The conserved domains were indicated in the box and bZIP motif was underlined. Domains and motif were marked with an abbreviation such as HD (homeodomain), START (steroidogenic acute regulatory protein related lipid-transfer), MEKHLA and bZIP (basic leucine-zipper motif). 
in differentiating xylems and roots than the other tissues. This shows that the abundance of PagHD-ZIP III_I transcripts in stem tissue is a unique feature of HD-ZIP III in Populus alba $\times$ P. glandulosa.

\section{Effects of abiotic stress and plant hormone treatments} on PagHD-ZIP III_1 expression

We performed another set of RT-qPCR to gain more insights into the expression patterns of PagHD-ZIP III_l in response to the treatments of various abiotic stresses and plant hormones. The levels of PagHD-ZIP III_l transcript in suspension cells were 2.7- and 2.9-fold highly expressed two hours after $\mathrm{NaCl}$ and low temperature treatments, respectively (Fig. 5A). HD-ZIP genes in plants were shown to be differentially expressed in response to different environmental cues. For example, Arabidopsis ATHB7

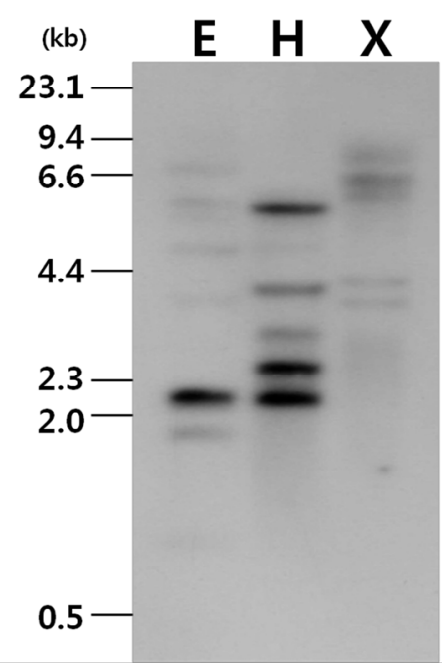

Fig. 3. Genomic Southern blot analysis of PagHD-ZIP III 1 in Populus alba $\times$ P. glandulosa. Genomic DNA digested with $\operatorname{EcoRI}(\mathrm{E})$, HindIII $(\mathrm{H})$ or $X b a \mathrm{I}(\mathrm{X})$, was fractionated by electrophoresis in an $1.0 \%$ agarose gel. The gel was blotted onto nylon membrane, and hybridized with ${ }^{32} \mathrm{P}$-labeled full-length PagHD-ZIP III_l cDNA.

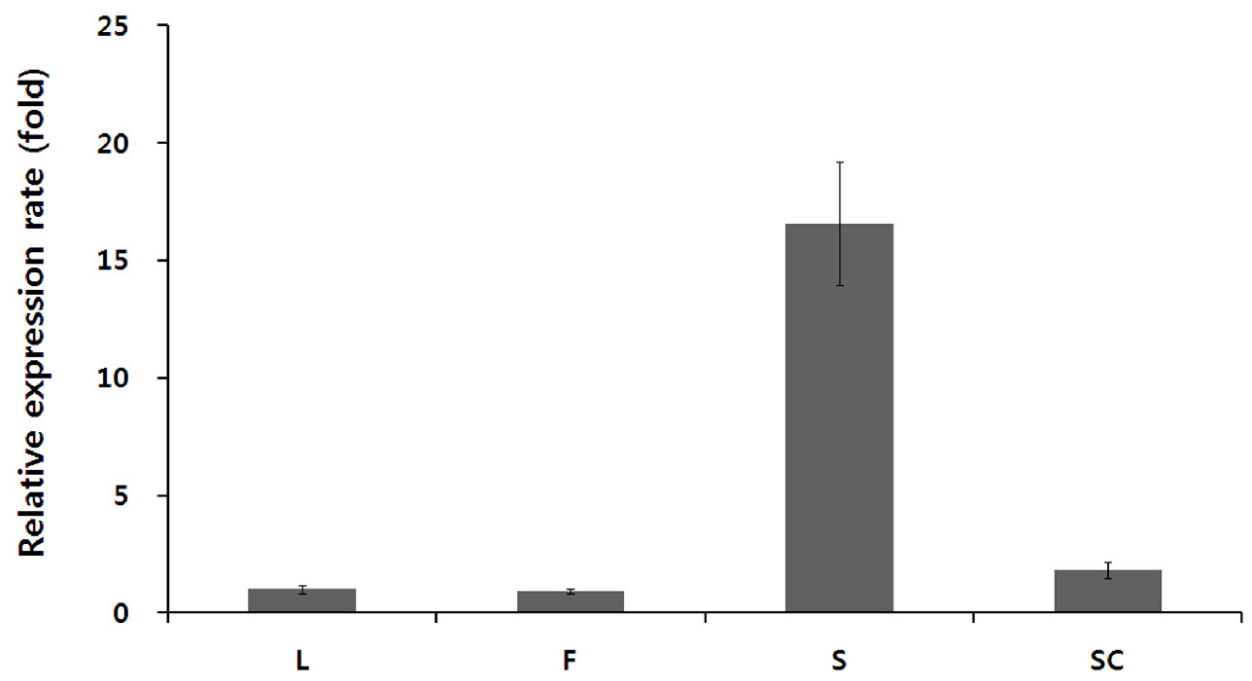

Fig. 4. Tissue-specific expression of PagHD-ZIP III_1. Total RNA was extracted from leaves (L), flowers (F), stems (S) and suspension cultured cells (SC) of Populus alba $\times$ P. glandulosa. Error bars show the standard deviation of expression levels. 
(A)

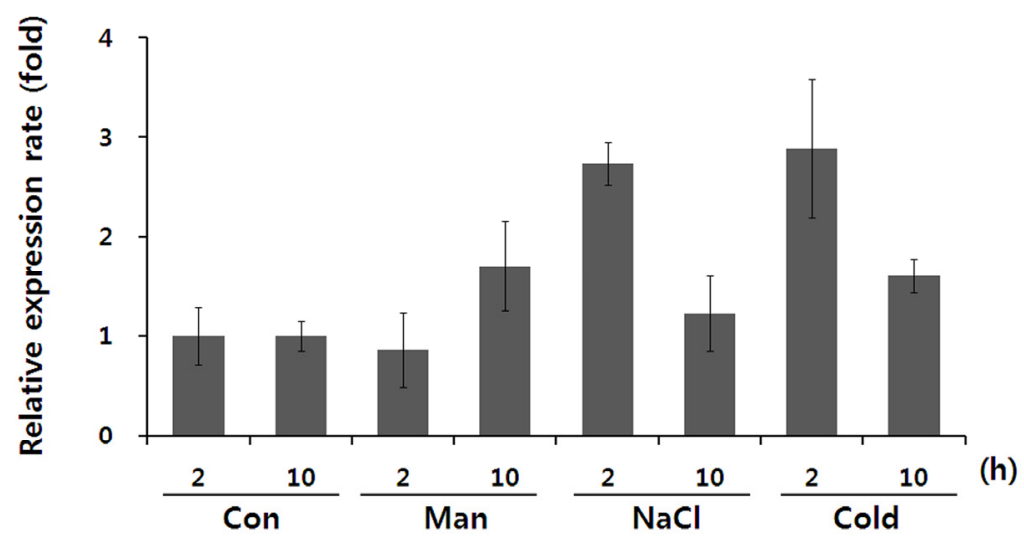

(B)

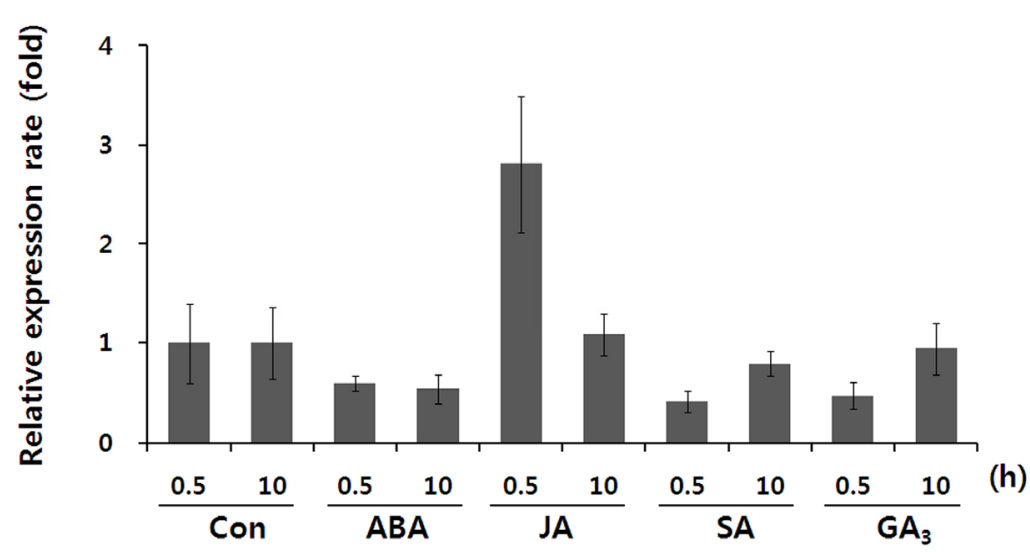

(C)

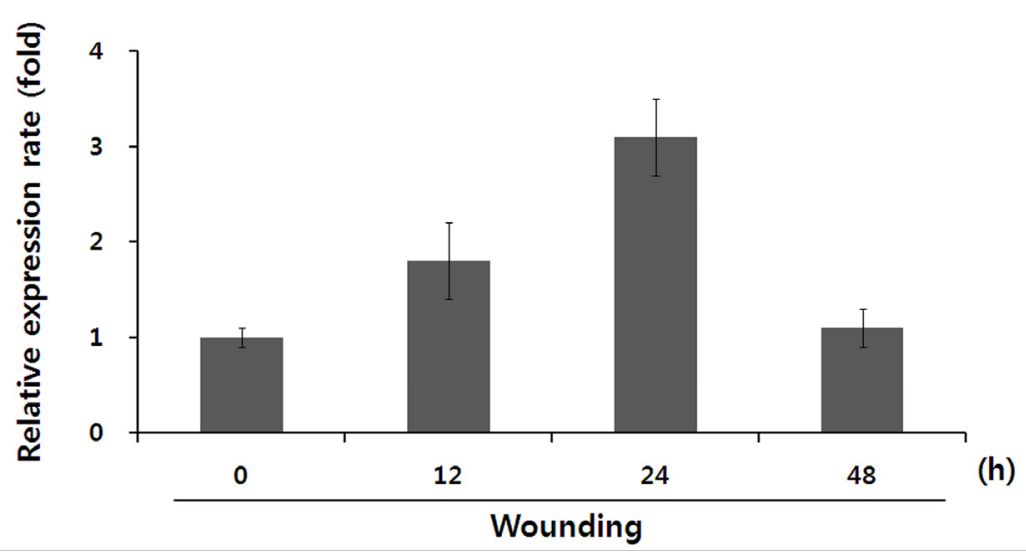

Fig. 5. PagHD-ZIP III_l expression under various treatment conditions. A. PagHD-ZIP III_l expression in response to treatment with mannitol, $\mathrm{NaCl}$ and cold for 2 and $10 \mathrm{~h}$. Untreated control cells were incubated for the same durations. PagHD-ZIP III_1 expression level represented as relative values when compared to those of untreated controls. B. PagHD-ZIP III_l expression in response to treatment with plant growth regulators including ABA, JA, SA and $\mathrm{GA}_{3}$ for 0.5 and 10 h. C. PagHD-ZIP III_l expression in response to wounding for 12, 24 and $48 \mathrm{~h}$. Total RNA was extracted from the trimmed leaves at the indicated times. Error bars show the standard deviation of expression levels. 
was induced in response to ABA and drought (Olsson et al. 2004), while HD-ZIPs in P. deltoides showed different expression patterns depending on the plant genotypes or the type of HD-ZIP genes (Hu et al. 2012).

The effects of exogenously applied plant hormones at physiological concentrations including JA, SA, $\mathrm{GA}_{3}$ and ABA on the expression level of PagHD-ZIP III_l were also examined. Among the plant hormone treatments, the expression level of PagHD-ZIP III_l was highly induced by JA with a 2.8 -fold increase (Fig. 5B). Hu et al. (2012) reported similar results showing that the treatment of methyl jasmonate increased the PtrHox 18 and 45 but reduced PtrHox6, 30, and 31 in suspension cells of a clone L4 of $P$. tremuloides. The increased expression of PagHD-ZIP III_l gene in the JA treatment indicated that this gene might be involved in JA signal transduction pathway. We therefore analyzed the expression of PagHD-ZIP III_l gene in response to mechanical damage on leaves of one-year-old plants. The expression levels of PagHD-ZIP III_l started to increase 12 hours after wounding and reached to the maximum level (3.1-fold) after 24 hours (Fig. 5C). Thereafter its expression leveled with the pre-treatment level (1.1-fold). The response of HD-ZIP genes to wounding treatment was also reported in P. tremuloides (Hu et al. 2012). When the mechanical damage was given on young leaves of poplar plants, PtrHox 17 and 23 were highly expressed but PtrHox 27 and 90 was down-regulated, showing that each HD-ZIP subfamily showed different expression patterns in response to wounding.

\section{CONCLUSION}

Although many studies have shown that HD-ZIP genes in plants played important roles in plant development, little is known about how such genes are regulated by various stresses and plant hormones. In this study, we showed that the PagHD-ZIP III_l gene was significantly induced in a hybrid poplar (Populus alba $\times$ P. glandulosa) in response to jasmonic acid, $\mathrm{NaCl}$, and low temperature, suggesting that the PagHD-ZIP III_l gene might be involved in not only jasmonic acid-mediated developmental process but also stress response. Since phytohormones play a key role in plant development and response to biotic and abiotic stresses, we expect that this study may enhance our understanding on the functional characterization of PagHD-ZIP III_1. Further study such as transgenic modification involving both gain and loss of function may be necessary to reveal the exact function of the protein and to enhance our understanding of its physiological role in poplar.

\section{REFERENCES}

Côté CL, Boileau F, Roy V, Ouellet M, Levasseur C, Morency MJ, Cooke JE, Séguin A, MacKay JJ. 2010. Gene family structure, expression and functional analysis of HD-ZIP III genes in angiosperm and gymnosperm forest trees. BMC Plant Biol. 10: 273.

Elhiti M, Stasolla C. 2009. Structure and function of homodomain-leucine zipper (HD-Zip) proteins. Plant Signal Behav. 4(2): 86-88.

Emery JF, Floyd SK, Alvarez J, Eshed Y, Hawker NP, Izhaki A, Baum SF, Bowman JL. 2003. Radial patterning of Arabidopsis shoots by class III HD-ZIP and KANADI genes. Curr. Biol. 13: 1768-1774.

Green KA, Prigge MJ, Katzman RB, Clark SE. 2005. CORONA, a member of the class III homeodomain leucine zipper gene family in Arabidopsis, regulates stem cell specification and organogenesis. Plant Cell 17: 691704.

Hu R, Chi X, Chai G, Kong Y, He G, Wang X, Shi D, Zhang D, Zhou G. 2012. Genome-wide identification, evolutionary expansion, and expression profile of homeodomain-leucine zipper gene family in poplar (Populus trichocarpa). PLoS One 7(2): e31149.

Jeong S, Volny M, Lukowitz W. 2012. Axis formation in Arabidopsis - transcription factors tell their side of the story. Curr. Opin. Plant Biol. 15(1): 4-9.

Johannesson H, Wang Y, Engstrom P. 2001. DNA- binding and dimerization preferences of Arabidopsis homeodomainleucine zipper transcription factors in vitro. Plant Mol. Biol. 45: 63-73.

Kim YH, Kim MD, Choi YI, Park SC, Yun DJ, Noh EW, Lee HS, Kwak SS. 2010. Transgenic poplar expressing Arabidopsis NDPK2 enhances growth as well as oxidative stress tolerance. Plant Biotechnol. J. 3: 334-347.

Lee H, Lee JS, Noh EW, Bae EK, Choi YI, Han MS. 2005. 
Generation and analysis of expressed sequence tags from poplar (Populus alba $\times$ P. tremula var. glandulosa) suspension cells. Plant Sci. 169: 1118-1124.

Lindemose S, O'Shea C, Jensen MK, Skriver K. 2013. Structure, function and networks of transcription factors involved in abiotic stress responses. Int. J. Mol. Sci. 14(3): 5842-5878.

Livak KJ, Schmittgen TD. 2001. Analysis of relative gene expression data using real time quantitative PCR and the $2^{-\triangle \triangle \mathrm{Ct}}$ method. Methods 25: 402-408.

Long TA, Benfey PN. 2006. Transcription factors and hormones: new insights into plant cell differentiation. Curr. Opin. Cell Biol. 18(6): 710-714.

Mukherjee K, Bürglin TR. 2006. MEKHLA, a novel domain with similarity to PAS domains, is fused to plant homeodomain-leucine zipper III proteins. Plant Physiol. 140(4): 1142-1150.

Murashige T, Skoog FA. 1962. Revised medium for rapid growth and bioassay with tobacco tissue culture. Physiol. Plant. 15: 473-497.

Ohashi-Ito K, Fukuda H. 2003. HD-ZIP III homeobox genes that include a novel member, ZeHB-13 (Zinnia)/ ATHB-15
(Arabidopsis), are involved in procambium and xylem cell differentiation. Plant Cell Physiol. 44: 1350-1358.

Olsson AS, Engstrom P, Soderman E. 2004. The homeobox genes ATHB12 and ATHB7 encode potential regulators of growth in response to water deficit in Arabidopsis. Plant Mol. Biol. 55: 663-677.

Prigge MJ, Otsuga D, Alonso JM, Ecker JR, Drews GN, Clark SE. 2005. Class III homeodomain-leucine zipper gene family members have overlapping, antagonistic, and distinct roles in Arabidopsis development. Plant Cell 17(1): 61-76.

Robischon M, Du J, Miura E, Groover A. 2011. The Populus class III HD ZIP, popREVOLUTA, influences cambium initiation and patterning of woody stems. Plant Physiol. 155(3): 1214-1225.

Schrick K, Nguyen D, Karlowski WM, Mayer KF. 2004. START lipid/sterol-binding domains are amplified in plants and are predominantly associated with homeodomain transcription factors. Genome Biol. 5: R41.

Southern EM. 1975. Detection of specific sequences among DNA fragments. J. Mol. Biol. 98: 503-517. 